\title{
Molecular characterization of misidentified Plasmodium ovale imported cases in Singapore
}

\author{
Jean-Marc Chavatte ${ }^{1 *}$, Sarah Bee Hui Tan', Georges Snounou ${ }^{2,3}$ and Raymond Tzer Pin Valentine Lin 1,4,5
}

\begin{abstract}
Background: Plasmodium ovale, considered the rarest of the malaria parasites of humans, consists of two morphologically identical but genetically distinct sympatric species, Plasmodium ovale curtisi and Plasmodium ovale wallikeri. These parasites resemble morphologically to Plasmodium vivax with which they also share a tertian periodicity and the ability to cause relapses, making them easily misidentified as $P$. vivax. Plasmodium ovale infections are rarely reported, but given the likelihood of misidentification, their prevalence might be underestimated.

Methods: Morphological and molecular analysis of confirmed malaria cases admitted in Singapore in 2012-2014 detected nine imported $P$. ovale cases that had been misidentified as P. vivax. Since P. ovale had not been previously officially reported in Singapore, a retrospective analysis of available, frozen, archival blood samples was performed and returned two additional misidentified $P$. ovale cases in 2003 and 2006. These eleven P. ovale samples were characterized with respect to seven molecular markers (ssrRNA, Potra, Porbp2, Pog3p, dhfr-ts, cytb, cox 1) used in recent studies to distinguish between the two sympatric species, and to a further three genes (tufa, clpC and as).

Results: The morphological features of $P$. ovale and the differential diagnosis with $P$. vivax were reviewed and illustrated by microphotographs. The genetic dimorphism between P. ovale curtisi and P. ovale wallikeri was assessed by ten molecular markers distributed across the three genomes of the parasite (Genbank KP050361-KP050470). The data obtained for seven of these markers were compared with those published and confirmed that both P. ovale species were present. This dimorphism was also confirmed for the first time on: (1) two genes from the apicoplast genome (tufA and ClpC genes); and, (2) the as/ gene that was used for phylogenetic analyses of other Plasmodium species, and that was found to harbour the highest number of dimorphic loci between the two P. ovale species.
\end{abstract}

Conclusion: Misidentified $P$. ovale infections are reported for the first time among imported malaria cases in Singapore. Genetic dimorphism between P. ovale curtisi and P. ovale wallikeri was confirmed using markers from the parasites' three genomes. The apparent increase of imported P. ovale since 2012 (with yearly detection of cases) is puzzling. Given decrease in the overall number of malaria cases recorded in Singapore since 2010 the'resurgence' of this neglected species raises public health concerns.

Keywords: Plasmodium ovale curtisi, Plasmodium ovale wallikeri, Singapore, Imported cases, Misidentification, Morphology, Molecular characterization

\footnotetext{
*Correspondence: jean-marc_chavatte@moh.gov.sg

${ }^{1}$ Malaria Reference Centre - National Public Health Laboratory,

Ministry of Health, Singapore, 3 Biopolis Drive, Synapse \#05-14/16,

138623 Singapore, Singapore

Full list of author information is available at the end of the article
} 


\section{Background}

The formal description of Plasmodium ovale by Stephens in 1922 [1] was made more than 30 years after that of the other three species that naturally infect humans. However, its morphological resemblance to Plasmodium vivax delayed its acceptance as a bona fide species by many years $[2,3]$. The clinical symptoms of primary $P$. ovale infections are typical of malarial infections (tertian high fever, chills, aches, and rigours) and the disease rarely progresses to severity although at least one fatal case was reported recently [4]. Peak parasitaemia is relatively low, and the infection often self-resolves, but with a tendency to re-appear even after effective treatment with schizontocidal drugs, as this species shares with $P$. vivax the ability to generate hypnozoites, dormant liver stages that activate weeks or months later and lead to a relapse episode [5]. Given the rarity of clinical severity, $P$. ovale has been used in malariotherapy for the treatment of neurosyphilis from 1930 to the 1960s [5-8], thereby providing data on the natural course of infection and the acquisition of immunity.

Plasmodium ovale occurs principally in West Africa and the Southwest Pacific where it can account for more than $10 \%$ of all malaria infections. Outside these regions, its prevalence is generally quite low $(<5 \%$, and often it is very rarely encountered), and its presence is yet to be confirmed in the Americas [9-16]. However, results from surveys based on sensitive molecular detection assays indicate that routine light microscopic examination of blood smears has underestimated its true prevalence [17-20]. In the course of such molecular surveys, a dimorphism in the $18 \mathrm{~S}$ small sub-unit ribosomal RNA (ssrRNA) genes was discovered, and the otherwise morphologically similar $P$. ovale parasites were divided into 'classical' and 'variant' types [21, 22]. The dimorphism was later found to extend to other $P$. ovale genes, which led to the proposal that $P$. ovale is actually a species complex comprising two sympatric species: Plasmodium ovale curtisi (classic type) and Plasmodium ovale wallikeri (variant type) [23]. These two parasites have been observed in diverse endemic areas [24, 25], and the presence of a variant type was reported in a chimpanzee from Cameroon [26].

Singapore was officially declared free from malaria in November 1982 [27] after an assiduous anti-malarial programme initiated in 1911, which was only disrupted during World War II [28-30]. Nevertheless, Singapore remains highly vulnerable to the re-emergence of malaria due to the natural presence of competent vectors and the large number of foreigners arriving from malariaendemic countries. Thus, 29 outbreaks of malaria have been reported in Singapore between 1983 and 2007 [31] and a focus of autochthonous transmissions of $P$. vivax confirmed in 2009 [32]. Furthermore, rare local zoonotic transmission of Plasmodium knowlesi has been recorded [33-35]. Surveillance and epidemiological monitoring of malaria cases are managed by the Ministry of Health $(\mathrm{MOH})$ in close collaboration with the National Environmental Agency (NEA) which implements measures to control vector populations. The Malaria Reference Centre (MRC) relocated from the National University of Singapore (NUS) to the National Public Health Laboratory (NPHL) in 2010, along with the clinical malaria notification reports and their related blood smears collection (1994-2008), 226 frozen blood samples (collected from 2001 to 2008), and the submitted clinical malaria-positive samples from 2009. Since 2010, all notified malariapositive clinical samples are sent directly to MRC-NPHL where a systematic species confirmation of all malariapositive cases notified in Singapore is carried out both by classical morphology [36-38] and by a polymerase chain reaction (PCR) assay [39]. These data contribute to the malaria surveillance programme that aims to validate the routine morphological testing performed by the clinical laboratories, and to monitor any outbreaks or cases of reintroduction of malaria in Singapore.

Cases of $P$. ovale have never been officially reported in Singapore (Pr. Goh KT, pers. comm.), but examination of the reports from the country's clinical laboratories from 1994 to 2014 revealed two cases: (1) a suspected $P$. ovale infection mixed with Plasmodium falciparum in 1998, although the morphological examination by the MRC was inconclusive at that time; and, (2) a suspected $P$. ovale infection in 2013 that was later confirmed to be $P$. vivax by MRC-NPHL. This report presents evidence of recently imported $P$. ovale infections in Singapore that had been misidentified as $P$. vivax, and includes a description of morphological and molecular characteristics of these parasites.

\section{Methods}

Samples from malaria-positive cases, Singapore (20012014)

From 2001 to 2014, a total of 2158 positive malaria cases, mainly imported, were notified to $\mathrm{MOH}$ by the clinical laboratories. For the period 2009-2014, a total of 830 positive malaria cases were directly received in MRCNPHL and the infecting species was confirmed for all by morphology and by molecular methods. For the earlier period 2001-2008, archived frozen blood samples were available for 226 cases, and these were retrospectively tested as above. Thus, a total of 1,056 positive malaria cases recorded in Singapore were included in the present study. All the samples were collected for surveillance purpose for the $\mathrm{MOH}$ under the Infectious Diseases Act (Chapter 137), Part III-Control of Infectious Diseases 
within Singapore, section 7-Public Health Surveillance Programmes.

\section{Blood smears for microscopy}

For routine surveillance, thick and thin blood films were prepared using standard procedures. Briefly, for thin smears one drop of blood was spread to a monolayer onto a glass slide using the edge of another glass slide, quickly air dried, fixed with absolute methanol and stained $20 \mathrm{~min}$ by $10 \%$ Giemsa stain (Merck, Singapore) in $\mathrm{pH}=7.2$ phosphate buffer; for thick smears one drop of blood was smeared onto a glass slide, slowly and fully dried at room temperature or in an incubator, de-haemoglobinized in water and stained $8 \mathrm{~min}$ by $10 \%$ Giemsa stain (Merck, Singapore) in $\mathrm{pH}=7.2$ phosphate buffer. Then all the smears were protected by a cover slip mounted with Eukitt ${ }^{\circledR}$ (Sigma-Aldrich, Singapore) mounting medium and dried before reading. Blood smears were examined under $\times 1000$ magnification with an Olympus CX31 microscope (Olympus, Singapore) and microphotographs taken with a Nikon Eclipse 80i microscope equipped with a Nikon DS Ril camera and the Nikon NIS Elements D Imaging Software (Nikon, Singapore).

\section{Blood DNA extraction}

For routine surveillance, DNA was extracted using the $\mathrm{EZ1}^{\circledR}{ }^{\circledR}$ Advanced XL and the EZ1 ${ }^{\circledR}$ DNA Blood $200 \mu \mathrm{L}$ Kit (Qiagen ${ }^{\circledR}$, Singapore) from $200 \mu \mathrm{L}$ whole blood collected on EDTA following the manufacturers' recommendations. The DNA template obtained was eluted in $200 \mu \mathrm{L}$ stored at $-30{ }^{\circ} \mathrm{C}$ until use.

\section{Identification of Plasmodium species by PCR}

The protocol for routine surveillance includes two consecutive steps: first, a fast real-time PCR (rt-PCR) screen for the presence of malaria parasites by targeting a $186 \mathrm{bp}$ fragment of the ssrRNA genes. The reactions are carried out using the StepOne ${ }^{\mathrm{TM}}$ Plus Real-Time PCR System (Applied Biosystems ${ }^{\circledR}$, Singapore), each in a final volume of $20 \mu \mathrm{L}$ containing $10 \mu \mathrm{L}$ of QuantiFast ${ }^{\mathrm{TM}}$ Probe master mix (Qiagen ${ }^{\circledR}$, Singapore), $0.4 \mu \mathrm{M}$ of each primer, $0.2 \mu \mathrm{M}$ of each probe, $4 \mu \mathrm{L}$ of nuclease free water, and $4 \mu \mathrm{L}$ of DNA template, as previously described [40]. Samples found positive were then subjected to published nestedPCR (nt-PCR) assays that allow determination of the species, including $P$. knowlesi $[39,41]$. All the reactions were run on Veriti ${ }^{\circledR}$ Thermal Cycler (Applied Biosystems ${ }^{\circledR}$, Singapore) following the cycling conditions described in $[39,41]$ and PCR products were visualized after electrophoresis using the QIAxcel ${ }^{\circledR}$ Advanced instrument (Qiagen $^{\circledR}$, Singapore).

\section{Genetic characterization of Plasmodium ovale}

In order to analyse genetic diversity, defined regions from ten different genes were amplified and then sequenced from all confirmed $P$. ovale-infected samples. All amplification reactions were run on Veriti ${ }^{\circledR}$ Thermal Cycler (Applied Biosystems ${ }^{\circledR}$, Singapore) and PCR products were visualized after electrophoresis using the QIAxcel $^{\circledR}$ Advanced instrument (Qiagen ${ }^{\circledR}$, Singapore). The PCR products form all the assays were purified using the QIAquick $^{\circledR}$ PCR Purification Kit (Qiagen ${ }^{\circledR}$, Singapore) following manufacturers' recommendations, eluted in $30 \mu \mathrm{L}$ of nuclease free $\mathrm{H}_{2} \mathrm{O}$ and stored at $-30{ }^{\circ} \mathrm{C}$ until use.

In order to achieve a fuller characterization of the $P$. ovale samples, genes belonging to the three genomes of the parasite were amplified and sequenced: (1) fragments of five nuclear genes that had been used previously to characterize the two $P$. ovale species: the $18 \mathrm{~S}$ small subunit ribosomal RNA gene (ssrRNA), the reticulocyte binding protein 2 gene (Porbp2), the glyceraldehyde3-phosphatase gene (Pog3p), the tryptophan rich antigen gene (Potra), and the dihydrofolate reductase thymidylate synthase gene $(d h f r-t s)$, as well as a gene used for evolutionary studies of Plasmodium that had not been previously characterized for $P$. ovale, the adenylosuccinate lyase gene (asl); (2) fragments of two conserved genes from the mitochondrial genome commonly used for phylogenetic and evolution studies: the cytochrome c oxidase 1 gene (cox 1$)$ and the cytochrome b gene $(c y t b)$ were amplified and sequenced; and, (3) fragments of two conserved genes present on the apicoplast genome used for evolution studies that had not been previously characterized for $P$. ovale: the elongation factor Tu gene (tufA) and the caseinolytic protease $\mathrm{C}$ gene $(\operatorname{clp} C)$.

ssrRNA fragments were obtained through a nested PCR assay [39] with the primary amplification carried out with the rPLU1 + rPLU5 primer pair and the secondary reaction with the rPLU3 + rPLU2 primer pair, leading to the amplification of a fragment of about $862 \mathrm{bp}[23,25]$. Porbp2, Potra and Pog3p fragments were obtained via a single PCR amplification as previously described [23] to yield fragments of $793 \mathrm{bp}$ for Porbp2, from $293 \mathrm{bp}$ to $365 \mathrm{bp}$ for Potra, and $662 \mathrm{bp}$ for Pog3p.

dhfr-ts fragments were obtained via a nested PCR amplification using a modified protocol based on previously published methods $[23,42]$. The primary reaction is performed with one set of pan-Plasmodium primers (PladhfrF-Pla-dhfrR) to yield a fragment of about $1925 \mathrm{bp}$, which was used as a template for secondary semi-nested amplifications performed with one of the primers used in the first amplification, paired with one $P$. ovale-specific oligonucleotide primers (Pla-dhfrF + Po5gsp2 and 
Po3gsp1 + Pla-dhfrR) to yield two overlapping fragments of about $870 \mathrm{bp}$ and $1160 \mathrm{bp}$, respectively. Both products were sequenced to obtain the full $d h f r$-ts gene.

asl fragments were obtained with a newly developed single PCR amplification using one set of pan-Plasmodium oligonucleotide primers: asl-F (5'-CCMATCGAYGGGMGRTACAAA- ${ }^{\prime}$ ) and asl-R (5'-TGTAAATTHCCYTCWGCATTTTC-3') to obtain a fragment of about $915 \mathrm{bp}$. This amplification reaction is carried out in a total volume of $20 \mu \mathrm{L}$ containing $1 \mathrm{X}$ High Fidelity PCR Buffer, $3 \mathrm{mM}$ of $\mathrm{MgSO}_{4}, 0.5 \mathrm{U}$ of Platinum ${ }^{\circledR}$ Taq DNA Polymerase High Fidelity (Invitrogen ${ }^{\mathrm{TM}}$, Singapore), $0.2 \mathrm{mM}$ of each dNTP (Promega, Singapore), $0.25 \mu \mathrm{M}$ of each primer and $1.5 \mu \mathrm{L}$ of the original DNA template. After an initial denaturation at $95^{\circ} \mathrm{C}$ for $3 \mathrm{~min}$, the cycling conditions were $94{ }^{\circ} \mathrm{C}$ for $30 \mathrm{~s}, 53^{\circ} \mathrm{C}$ for $1 \mathrm{~min}$ and $68^{\circ} \mathrm{C}$ for $1 \mathrm{~min}$ followed by a final extension at $68^{\circ} \mathrm{C}$ for $10 \mathrm{~min}$.

cox1 fragments were obtained using a nested PCR protocol as previously described [26], to yield a fragment of about 1412 bp. Cytb fragments were obtained using a nested PCR protocol as previously described [43], to yield a fragment of about $1175 \mathrm{bp}$.

tufa fragments were obtained using a nested PCR protocol as previously described [44], to yield a fragment of about 814 bp. $c l p C$ fragments were obtained using a single PCR amplification as previously described [44], to yield a fragment of about $647 \mathrm{bp}$.

\section{Sequencing}

The purified PCR products were sequenced in both direction using the BigDye ${ }^{\circledR}$ Terminator v3.1 cycle sequencing Kit (Applied Biosystems ${ }^{\circledR}$, Singapore) using the appropriate oligonucleotide primers, following manufacturers' recommendations. Then the BigDye ${ }^{\circledR}$ reaction's products were purified using the BigDye ${ }^{\circledR}$ XTerminator $^{\mathrm{TM}}$ Purification Kit (Applied Biosystems ${ }^{\circledR}$, Singapore) following manufacturers' recommendations before being sequenced on a $3500 \times 1$ Genetic Analyzer (Applied Biosystems ${ }^{\circledR}$, Singapore).

\section{Sequences analysis}

Alignment and cross-checking of the sequences were performed with CLC Main Workbench 5.7 software (CLC bio-Qiagen ${ }^{\circledR}$, Singapore. Multiple alignments of the sequences with published sequences from GenBank were created to study the polymorphism between the two $P$. ovale species at key loci for each gene.

\section{Phylogenetic analyses}

Molecular phylogenies were derived from a $\approx 800 \mathrm{bp}$ fragment of the asl gene by maximum likelihood (ML) method with GTR $+\mathrm{I}+\Gamma$ model using PhyML software and by neighbour joining (NJ) method with J-C model using BioNJ algorithm. Nodal robustness of the tree was evaluated by non-parametric bootstrapping (1000 replicates).

\section{Results}

\section{Detection of imported Plasmodium ovale cases} in Singapore

Among the 316 cases notified to $\mathrm{MOH}$ by the clinical laboratories for the 2012-2014 period, nine cases reported as $P$. vivax have been re-identified as $P$. ovale by the MRC-NPHL (2012 $\mathrm{n}=4,2013 \mathrm{n}=3$ and $2014 \mathrm{n}=2)$. As a consequence of these misidentifications, the MRCNPHL conducted a retrospective study using the same combined morphological and molecular approaches on the 226 available malaria-positive, frozen blood samples collected between 2001 and 2008 in Singapore, and on samples from all the cases $(\mathrm{n}=511)$ recorded during 2009-2011. This test returned a further two P. ovale-positive cases, one in 2003 and one in 2006, both misdiagnosed as $P$. vivax. Details of the reports and case histories for all known $P$. ovale cases in Singapore are presented in Additional file 1 . To date, a single mixed infection case (not reconfirmed) and 11 pure infection $P$. ovale cases have been identified in Singapore.

\section{Morphological diagnosis}

All the confirmed $P$. ovale cases in Singapore have been misidentified as $P$. vivax by the routine morphological examination performed at the hospital laboratories (Additional file 1). Thus, it seems important and useful to include a description of the erythrocytic stages based on $[1,7,9,45]$.

\section{Description}

The merozoite of $P$. ovale preferentially invades a reticulocyte, hence most of the young stages of this parasite are found in young red blood cells (RBCs).

\section{Ring (Fig. 1a-c)}

The youngest ring stages have a prominent round nucleus (Fig. 1a-c) that is often detached from the wisp of the cytoplasm, with a central vacuole (Fig. 1b, c). As this early stage progresses, the infected RBC becomes enlarged. Sometimes, the outline of the infected RBC changes to a slightly oval shape. Fimbriation may occur and the stippling starts to appear (Fig. 1a-c). The amount of cytoplasm increases as the parasite develops.

\section{Trophozoite (Fig. 1d-g)}

In the young trophozoite, the vacuole reduces in size and tends to disappear later. The cytoplasm becomes more abundant (Fig. 1d-f) and could appear as 'pulled out' 


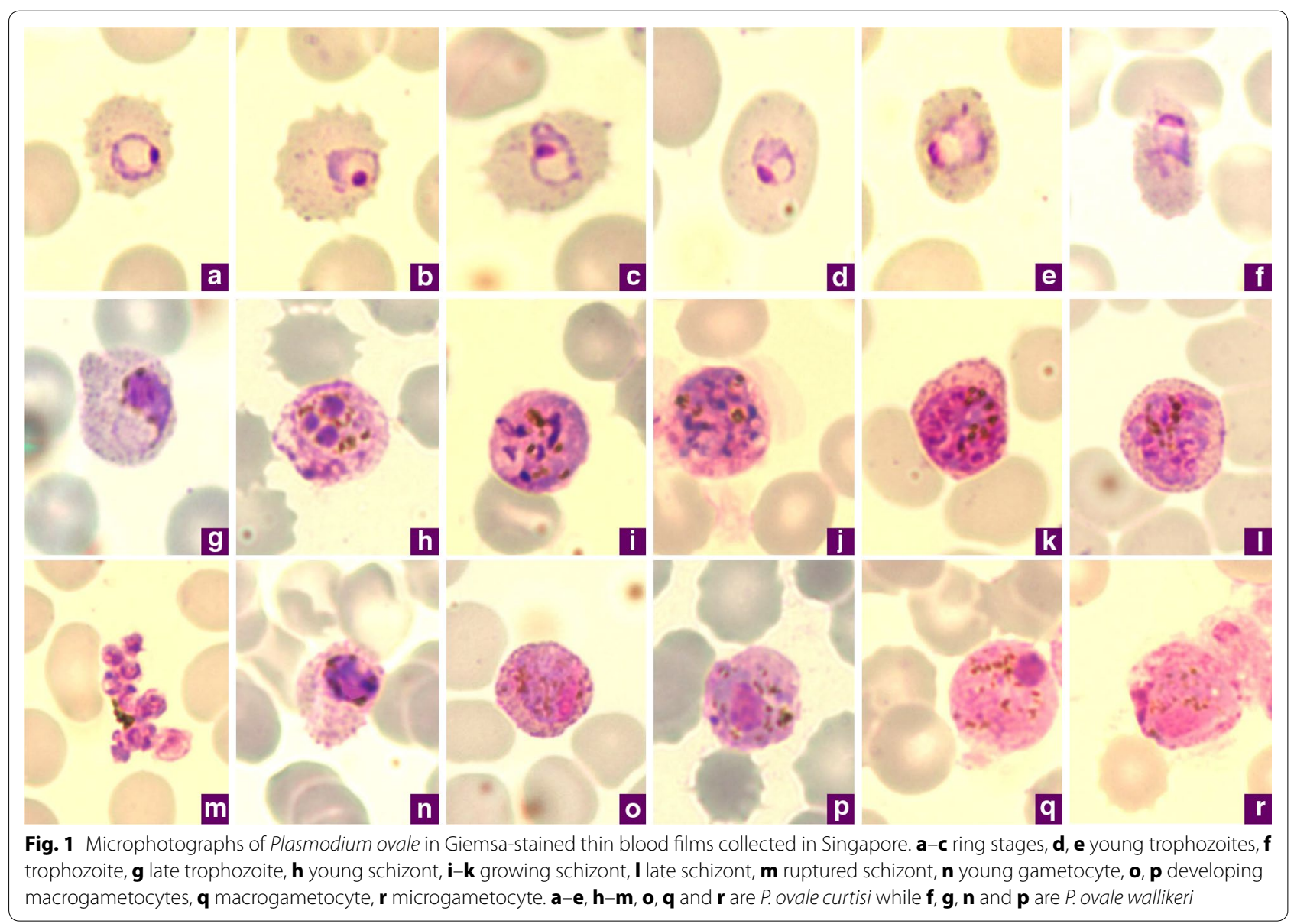

or ragged (Fig. 1g). Sometimes it is possible to observe unusual elongated trophozoites that resemble the band form of Plasmodium malariae. The stippling (known as Schüffner stippling) increases and covers the whole infected RBC (Fig. 1f, g), which may begin to appear really oval in shape (Fig. 1d, f) with fimbriated edges (Fig. 1f). At the same time the pigment appears as a fine dust, like brown grains (Fig. 1f). As the parasite grows, these grains aggregate in dark brown beads (Fig. 1g) and occasionally appear greenish as light is reflected off them. In the late trophozoite, the nucleus and the cytoplasm increases significantly in size (Fig. 1g) and the parasite may occupy up to half of the RBC. The typical schüffnerization progresses to larger and larger but regular red/violet dots that sometime obscure the infected RBC (Fig. 1f, g).

\section{Schizont (Fig. 1h-m)}

The prominent nucleus that appears as a deep red-staining mass in a lighter matrix starts to divide into nuclei that remain noticeably large (Fig. 1h). At this time the markedly blue-staining cytoplasm of the trophozoite can fade (Fig. 1f) before turning more purplish-blue in the late stages (Fig. 1i-l). The chromatin in the growing schizont is at first condensed (Fig. 1i) before it divides (Fig. 1j, k) to produce about eight nuclei (Fig. 1l). At the same time, the pigment grains continue to come together, although with no special localization within the infected RBC (Fig. 1i-k), and tend to form a single yellowishbrown patch (Fig. 1m). The Schüffner dots are more abundant and may darken the infected RBC (Fig. 1k, 1). At maturity (Fig. $1 \mathrm{~m}$ ), typically eight merozoites are formed (range from 4 to 16). Higher numbers of merozoites occur more often in patients that relapse and have chronic infection; they are less neatly arranged (Fig. 11) compared to those observed in a P. malariae schizont.

\section{Gametocytes (Fig. 1n-r)}

These usually appear late during the infection. The young gametocyte is difficult to distinguish from the compact late trophozoite, but generally the pigment is coarser and darker (Fig. 1n). As growth proceeds the gametocyte increases in size to fill the infected RBC completely. The changes to the infected $\mathrm{RBC}$ induced by the gametocytes are similar to those described for the asexual stages. The 


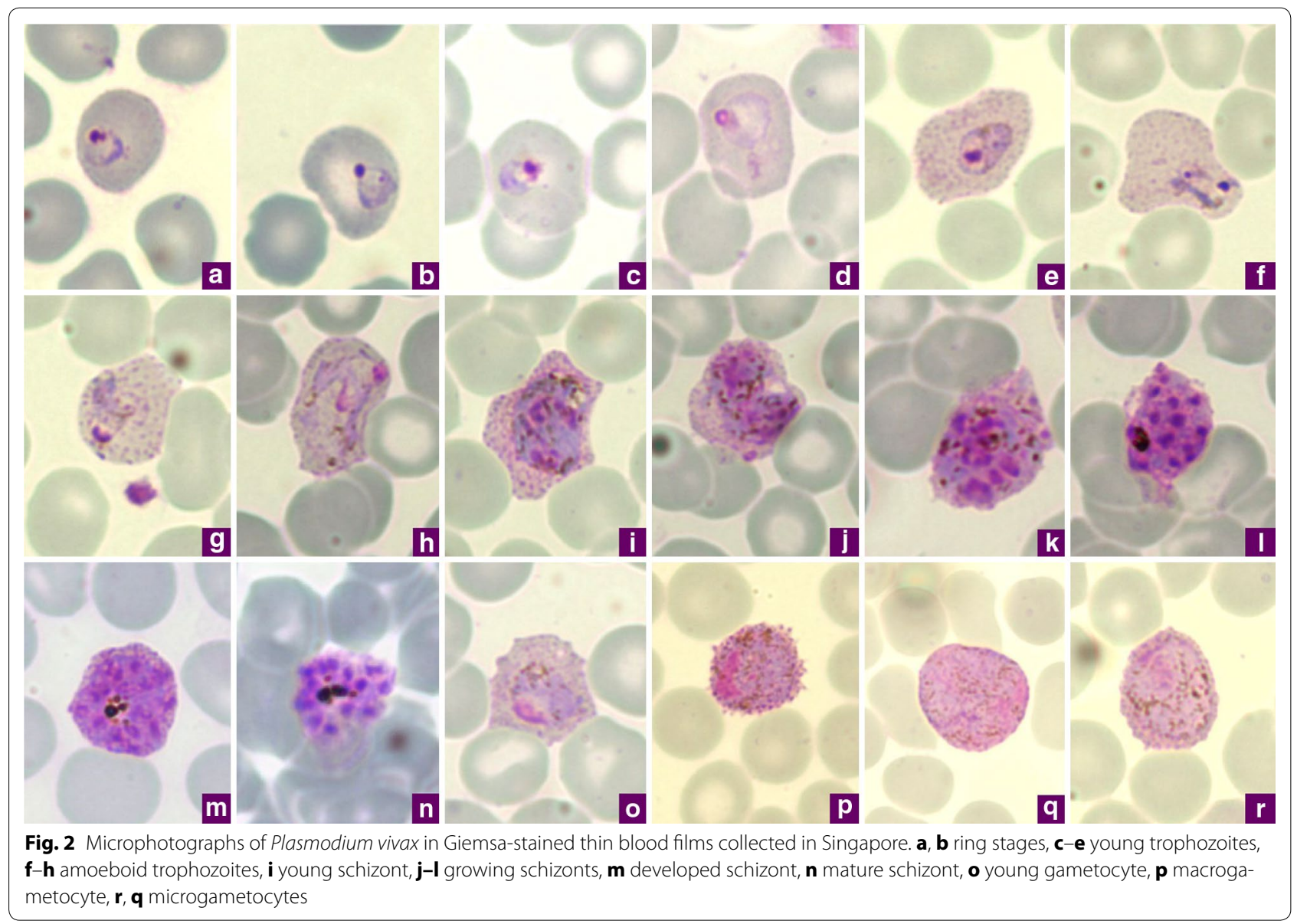

macrogametocyte has a medium blue-stained cytoplasm, the nucleus is large, compact and eccentrically located, with a non-homogenous distribution of dark red and light red staining, and generally adopts a semi-lunar to oval shape (Fig. 1o-q). The stippling of this stage is usually prominent (Fig. 1o-q), stains red, and is more or less organized in a ring around the parasite. The cytoplasm of the microgametocyte is pinker (Fig. 1r), with a very large nucleus that can occupy almost half of the parasite consists of areas that are stained a darker red, surrounded by a diffuse area of chromatin that fades to pale pink (Fig. 1r). Obvious and deep red-staining Schüffner dots encircle the parasite. The dark brown or black granules of pigment in the gametocyte are scattered throughout the cytoplasm (Fig. 1p, q), but occasionally in macrogametocytes they have a tendency to come together in a rod shape (Fig. 1p).

\section{Differential diagnostic}

In Giemsa-stained thin blood smears of the malaria parasite species usually found in humans (P. falciparum, P. vivax, $P$. malariae, $P$. ovale, and $P$. knowlesi), $P$. ovale could only be morphologically confused with $P$. vivax, the other tertian human malaria parasite that produces hypnozoite stages capable of inducing a relapse. In order to emphasize the differential diagnostic for $P$. ovale and $P$. vivax, comparative microphotographs of $P$. vivax are furnished in Fig. 2a-r. Additional details can be found in the comparison between the Donaldson strain of P. ovale with two strains of $P$. vivax [46].

In $P$, ovale infections, the infected $\mathrm{RBCs}$ are usually normal or just slightly enlarged (up to $1.25 \times$ ), while those infected with $P$. vivax (Fig. 2a-r) are usually more enlarged $(1.5 \times$ to up to $2 \times)$. The change in the shape of the infected RBC is another characteristic of $P$. ovale: a higher proportion of $P$. ovale-infected RBCs adopt a clear oval shape, whereas those infected by $P$. vivax display a distorted shape (Fig. 2e-j, m, o). The presence of infected RBCs with fimbriated edges, which seems to be linked to the smearing conditions, is indicative of $P$. ovale (Fig. 1a-c, f) where it occurs more frequently, but it can be observed for $P$. vivax. A detailed analysis of the changes in the outline of the infected RBCs can be found elsewhere [47]. 
In both $P$. ovale and $P$. vivax, the Schüffner dots are a good differential characteristic because in $P$. ovale the stippling appears and then covers the entire parasitized cell in the early stages (from young rings, Fig. 1a-d), while in $P$. vivax is appears later as the trophozoites develop (Fig. 2e-h). In addition, the stippling is often more pronounced than that observed in $P$. vivax and the dots are usually bigger, regular in size, red to violet in colour, and tend to darken the RBC.

Another element to consider is the parasite's nucleus. In the P. ovale trophozoite (Fig. $1 \mathrm{~g}$ ), the nucleus is almost double the size of that observed in $P$. vivax at the equivalent stage (Fig. $2 \mathrm{e}-\mathrm{h}$ ), even though the $P$. ovale parasite is smaller in size. Furthermore, following the first steps of schizogony, the patches of chromatin are bigger in $P$. ovale than those produced in a young $P$. vivax schizont. In the mature schizont, the number of merozoites produced by $P$. ovale is usually eight (range from 4-16) (Fig. $1 \mathrm{~m}$ ) while $P$. vivax mature schizonts usually contain 16 merozoites (range 16-24) (Fig. 2n).

The gametocytes of $P$. ovale (Fig. 1o-r) are smaller in size than those of $P$. vivax, their cytoplasm has a lighter purple-blue to pink stain, and their pigment is less abundant than that of P. vivax (Fig. 2o-r).

While there are clear features that allow the distinction of $P$. ovale from $P$. vivax as presented above, we have not observed any morphological differences between $P$. ovale curtisi and P. ovale wallikeri by morphology.

\section{Molecular characterization of Plasmodium ovale from the cases imported in Singapore}

In order to characterize the $P$. ovale parasites from the 11 cases imported in Singapore, genetic polymorphisms were sought on ten different loci spread across the three genomes of the parasites.

\section{Nuclear genes \\ ssrRNA}

This gene has long been used as a target for Plasmodium species identification, and the polymorphisms observed in this gene provided the first indication that $P$. ovale populations could be divided into 'classical' and 'variant' types. The sequences of the fragments (ca. $826 \mathrm{bp}$ ) amplified from the $P$. ovale samples from Singapore were compared (Fig. 3a; GenBank accession numbers KP050361 to KP050371) to those previously published [22, 23, 25, 48]. The parasites from eight samples were $P$. o. curtisi (Po 2003, Po 2012-1, Po 2012-2, Po 2012-4, Po 2013-1, Po 2013-2, Po 2013-3, and Po 2014-1), and the other three were P. o. wallikeri (Po 2006, Po 2012-3 and Po 2014-2). There was a higher diversity in the point mutations found for the P. o. wallikeri sequences, but the number of samples was too low to allow any meaningful conclusion.
Porbp2

The fragment (ca. $793 \mathrm{bp}$ ) analysed has been used previously to discriminate $P$. o. wallikeri from $P$. o. curtisi [23-25]. The sequences obtained for the 11 imported cases (Fig. 3b; GenBank accession numbers KP050394 to KP050404) fully concord with those published to date, and confirmed the species identification obtained using the ssrRNA locus.

\section{Pog3p}

The fragment (ca. $662 \mathrm{bp}$ ) analysed has been used previously to discriminate $P$. o. wallikeri from $P$. o. curtisi [23]. The sequences obtained for the 11 imported cases (Fig. 3c; GenBank accession numbers KP050383 to KP050393) fully concord with those published to data, and confirmed the species identification obtained using the ssrRNA locus.

\section{Potra}

The fragment of variable size (from 293 to $347 \mathrm{bp}$ ) that was analysed has been used previously to discriminate P. o. wallikeri from P. o. curtisi [23, 24, 49]. Comparison of the predicted amino acid sequences obtained for the 11 imported cases (Fig. 4a; GenBank accession numbers KP050372 to KP050382) confirmed the species identification obtained using the other loci. Furthermore, it showed that Po 2003, Po 2012-1, Po 2012-4, Po 2013-2, and Po 2014-1 are similar to P. o. curtisi type 1 [HM594182], while Po 2012-2, Po 2013-1 and Po 2013-3 are similar to $P$. o. curtisi type 2 [HM594183] which is distinguished by two 6-amino acid (PISTIT) repeat units $[23,24]$. Two of the three $P$. o. wallikeri sequences showed novel genotypes differing from previously published genotypes by the size of the repeat units (Pow type 1 [HM594180] and type 2 [HM594181]).

dhfr-ts

Non-synonymous mutations and differences in the number of amino acid repeat units have been reported for the dhfr-ts of P. o. curtisi and P. o. wallikeri $[23,50]$. Comparison of the complete gene sequences for the imported cases (GenBank accession numbers KP050405 to KP050415) with those published (Fig. 4b), confirmed the classification into two groups of eight $P$. o. curtisi and three $P$. o. wallikeri sequences, although some additional non-synonymous mutations were observed.

asl

This gene encodes the housekeeping protein adenylosuccinate lyase, an enzyme that is responsible for the salvage of host purines that are the used for DNA synthesis by Plasmodium [51]. The value of asl for phylogenetic and evolutionary studies of Plasmodium parasites has been 


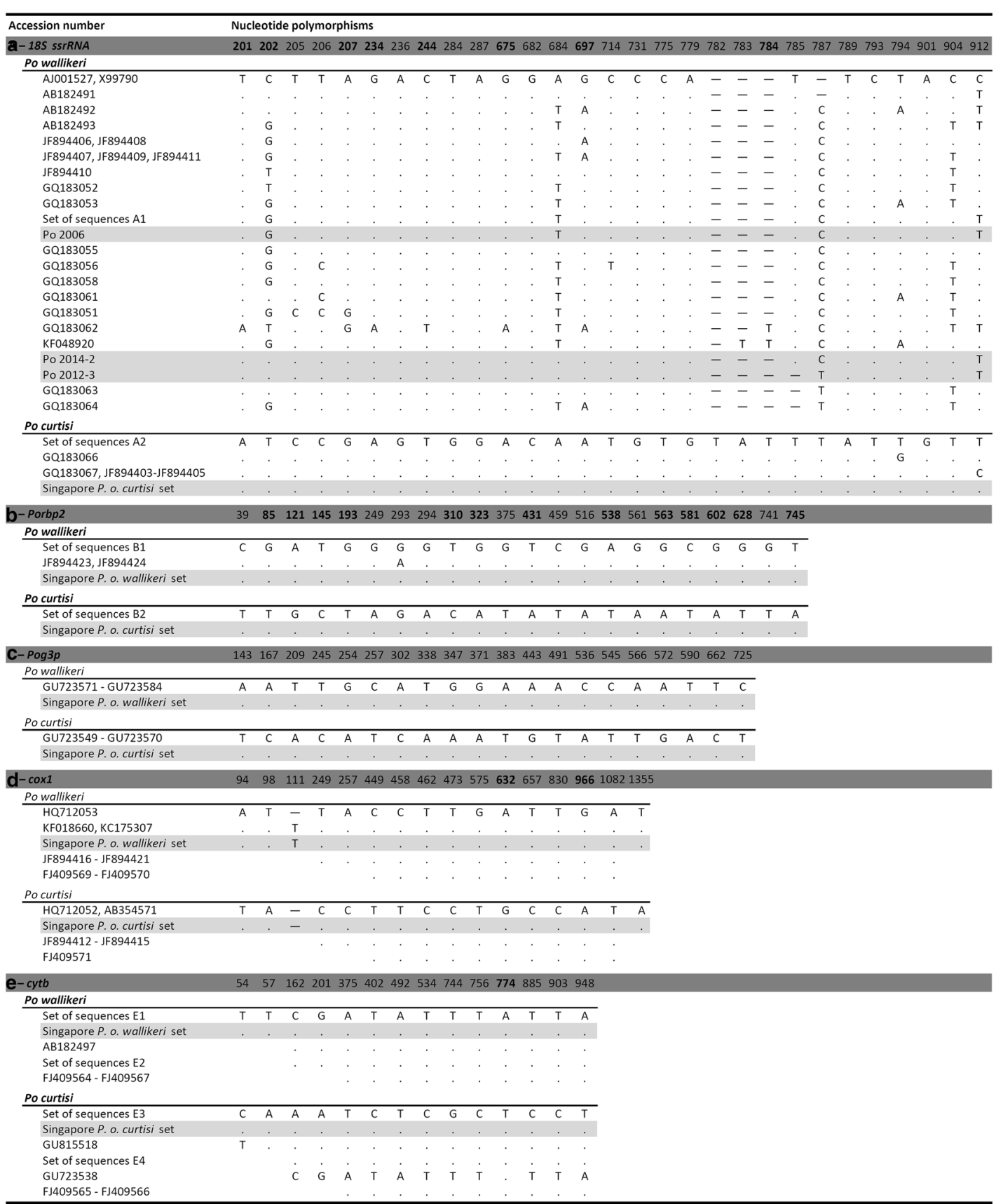

Fig. 3 Dimorphic nature of Plasmodium ovale curtisi and Plasmodium ovale wallikeri based on the partial sequences from three nuclear and two mitochondrial genes. a $18 \mathrm{~S}$ ssrRNA, b Porbp2, c Pog3p, d cox1, e cytb genes. Each alignment includes sequences from the P. ovale cases imported in Singapore (highlighted in grey) and from published sequences. Numbering is based for the $18 S$ ssrRNA gene on the asexually expressed (A type) gene [L48987], for the Porbp2 and Pog3p genes on the putative start-codons (ATG) identified by [23], for the cox1 gene on the homologous position of the P. falciparum cox1 gene [M76611], and for the cytb gene on the start-codon (ATG). For 18S ssrRNA gene the sets of sequences A1 and A2 contain: [L48986, L48987, AB182489, GQ231515, GQ183065, GQ183068] and [GU813972, JF894422, JF894425, JF894426] respectively; for Porbp2 gene the sets of sequences B1 and B2 contain: [GU813972, JF894422, JF894425, JF894426] and [GU813971, JF894427-JF894429] respectively; for cytb gene the sets of sequences E1 to E4 gene contain [HQ712053, GQ231518-GQ231520], [GU723535-GU723537, GU723539-GU723548], [HQ712052, AB354571, GQ231516-GQ231517] and [AB182496, AF069625, GU723514-GU723534], respectively. The Singapore P. o. wallikeri and Singapore P. o. curtisi sets represent for each gene the sequences obtained from [Po 2006, Po 2012-3 and Po-2014-2] and from [Po 2003, Po 2012-1, Po 2012-2, Po 2012-4, Po 2013-1, Po 2013-2, Po 2013-3 and Po-2014-1], respectively. Non-synonymous mutations are in boldface type, hyphens represent gaps, dots represent nucleic acid identity and blanks represent unavailable information 


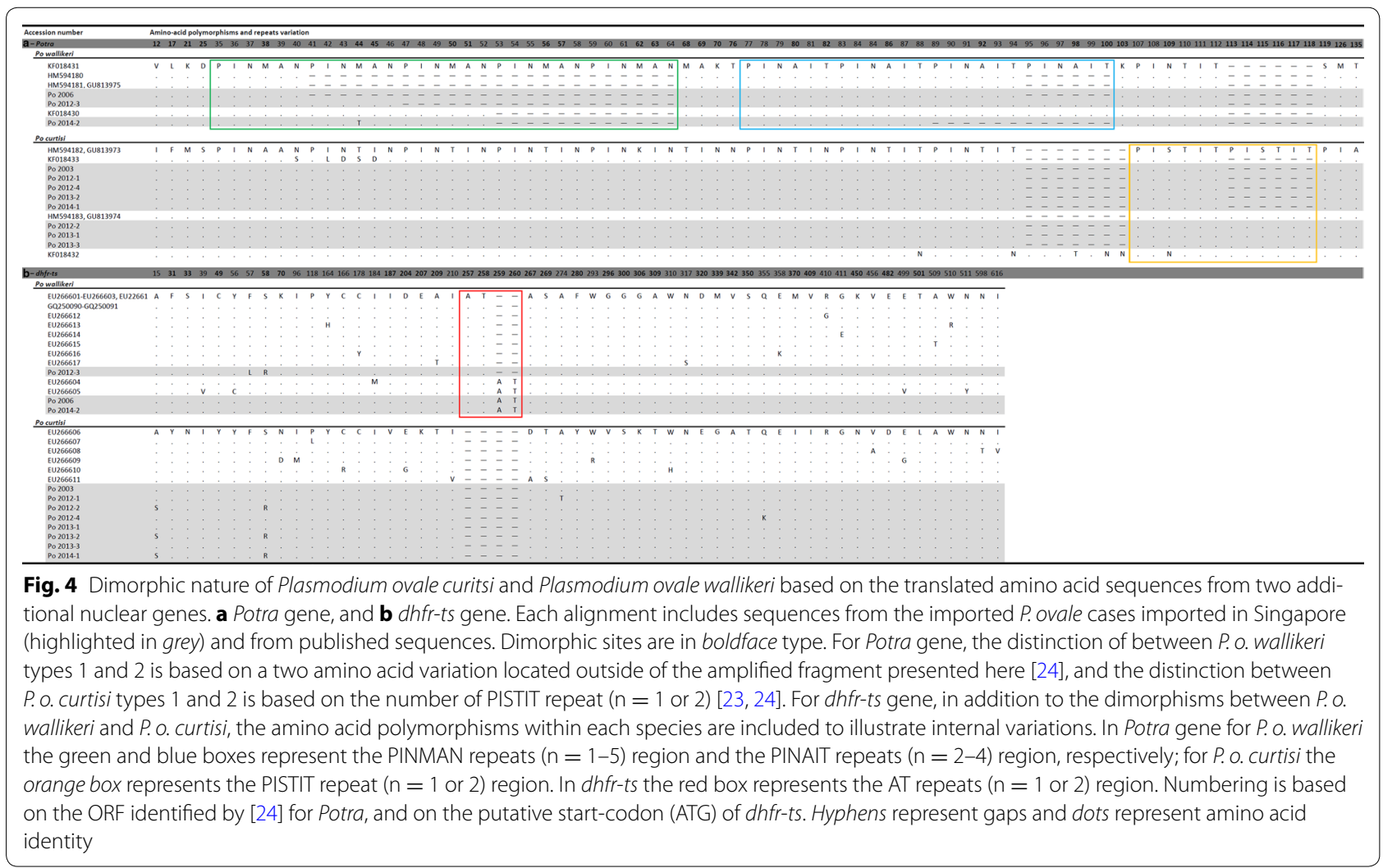

noted previously [52-54]. Amplification of asl was carried out for the $11 P$. ovale samples as well as for $P$. vivax, $P$. falciparum, $P$. malariae, and $P$. knowlesi samples from cases recorded in Singapore. A 841-bp fragment was obtained for all the samples, and all the sequenced derived (GenBank accession numbers KP050460 to KP050474) were added to published ones for the phylogenetic analyses (Fig. 5). Sequences for this gene were not hitherto available in GenBank for P. ovale and P. malariae. A total of 62 dimorphic loci have been identified between $P$. o. curtisi and P. o. wallikeri (Fig. 6). The number of dimorphic loci was higher than those recorded for the other genes studied in the present work. The two phylogenies obtained (Fig. 5) provided similar tree architecture, with all the $P$. ovale grouped within a biphyletic clade where $P$. o. curtisi and $P$. o. wallikeri are clearly separated.

\section{Mitochondrial genes}

cox 1

This gene is commonly used for phylogenetic and evolutionary studies, DNA bar-coding of metazoans, and to investigate $P$. o. curtisi and $P$. o. wallikeri $[25,26]$. A 1,412bp fragment was amplified from each sample (GenBank accession numbers KP050416 to KP050426) and their sequences were compared to published ones (Fig. 3d). The sequences from the 11 imported $P$. ovale cases matched perfectly with those published for $P$. $o$. curtisi and $P$. o. wallikeri for all the 15 dimorphic loci.

\section{cytb}

This gene is also commonly used for phylogenetic and evolutionary studies, and it has been used to discriminate between the two $P$. ovale species [23, 26]. A 1244-bp fragment was amplified from each of the imported $P$. ovale cases and their sequences (GenBank accession numbers KP050427 to KP050437) compared to those previously published (Fig. 3e), yielding the same conclusion as that from the $\operatorname{cox} 1$ gene above.

\section{Apicoplast genes}

Two conserved genes used for phylogenetic and evolutionary studies belong to the third genome of the parasite and are as yet uncharacterized for both the $P$. ovale species.

\section{tufA}

A single full $P$. ovale tufA sequence has been deposited in GenBank [AB649417] [55]. It originates from the Nigeria II strain that is classed as a $P$. o. curtisi, and has been compared to the sequences (GenBank accession numbers KP050449 to KP050459) of the 814-bp fragment amplified from each of the imported cases (Fig. 7a). A total of 

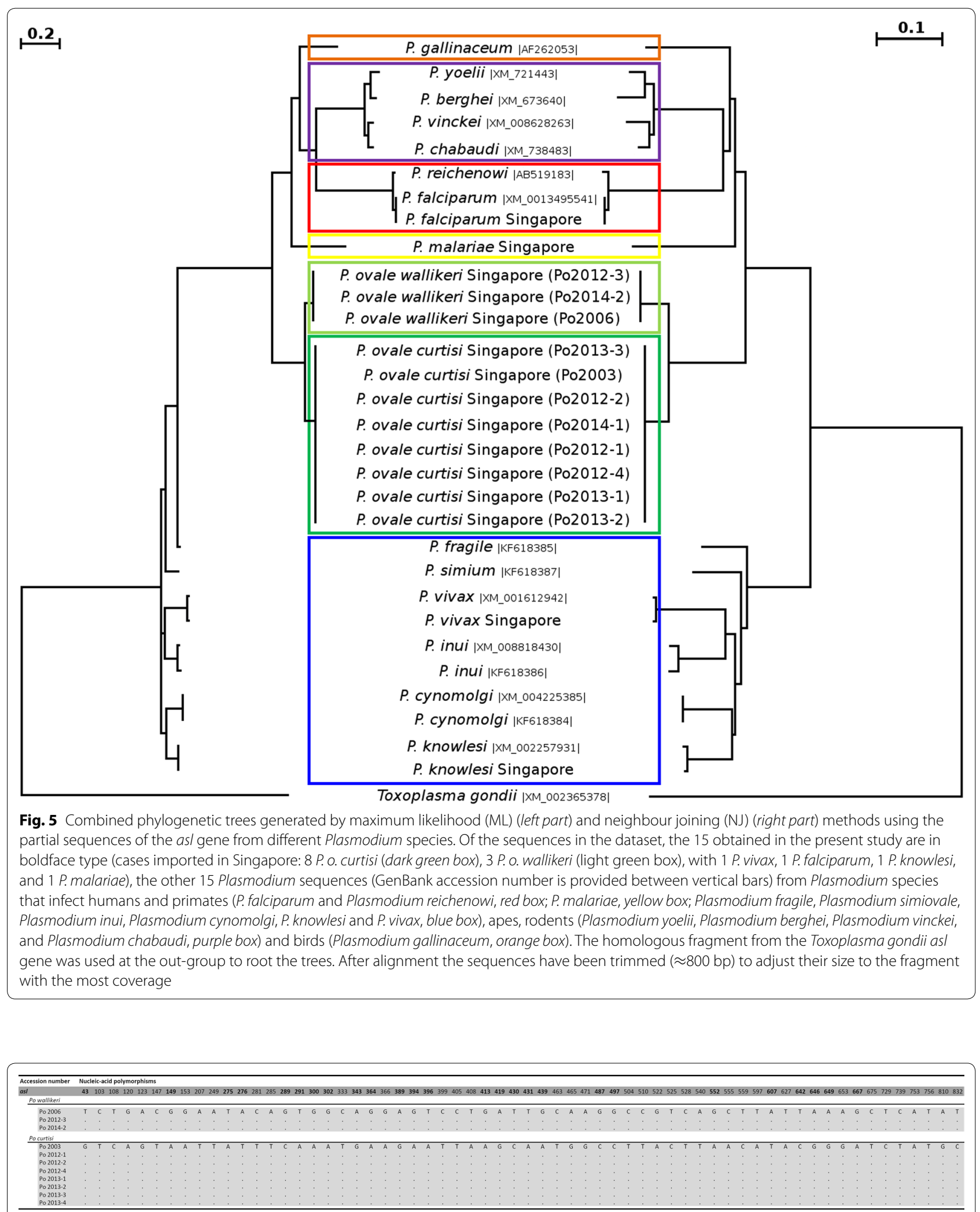

Fig. 6 Dimorphic nature of Plasmodium ovale curtisi and Plasmodium ovale wallikeri based on the partial sequences from the nuclear gene asl. The alignment highlights differences between P. o. curtisi on P. o. wallikeri at 62 loci. Numbering is based on the first nucleic acid of the forward oligonucleotide primer. Non-synonymous mutations are in boldface type, and dots represent nucleic acid identity 


\begin{tabular}{|c|c|c|c|c|c|c|c|c|c|c|c|c|c|c|c|c|c|c|c|}
\hline \multicolumn{20}{|c|}{ Accession number Nucleotide polymorphisms } \\
\hline a-TufA & 177 & 246 & 288 & 315 & 360 & 424 & 490 & 495 & 519 & 651 & 711 & 714 & 720 & 732 & 737 & 739 & 781 & 795 & 840 \\
\hline \multicolumn{20}{|l|}{ Po wallikeri } \\
\hline $\begin{array}{l}\text { Po 2006 } \\
\text { Po 2012-3 } \\
\text { Po 2014-2 }\end{array}$ & A & $\mathrm{c}$ & $\begin{array}{l}\mathrm{T} \\
\end{array}$ & $\begin{array}{l}T \\
\end{array}$ & $\begin{array}{l}\mathrm{G} \\
\mathrm{C}\end{array}$ & $\begin{array}{l}A \\
.\end{array}$ & G & $\begin{array}{l}\text { A } \\
\text {. }\end{array}$ & $G$ & A & $T$ & $T$ & $\begin{array}{l}\text { A } \\
\text {. }\end{array}$ & A & G & $\begin{array}{l}G \\
\text {. }\end{array}$ & $\begin{array}{l}\mathrm{T} \\
.\end{array}$ & $\begin{array}{l}\text { A } \\
.\end{array}$ & A \\
\hline \multicolumn{20}{|l|}{ Po curtisi } \\
\hline $\mathrm{AB} 649417$ & G & $\mathrm{T}$ & A & A & A & G & A & G & A & C & $\mathrm{A}$ & A & $T$ & G & A & A & A & $\mathrm{G}$ & $T$ \\
\hline Po 2003 & & . & . & . & . & . & . & . & 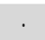 & . & & 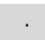 & . & . & . & . & . & . & . \\
\hline Po 2012-1 & & 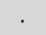 & . & . & . & . & . & . & . & . & & & . & . & . & . & . & . & . \\
\hline Po $2012-2$ & & . & . & . & . & . & . & . & . & . & & & . & . & . & . & . & . & r. \\
\hline Po 2012-4 & & . & . & . & . & . & . & . & . & . & & & . & . & . & . & . & . & r. \\
\hline Po 2013-1 & & . & . & . & . & . & . & . & & . & & & . & . & . & . & . & . & r. \\
\hline Po 2013-2 & & & . & . & . & . & . & . & & & & & & . & . & . & . & . & \\
\hline Po 2013-3 & & . & . & . & . & . & . & . & & . & & & . & . & . & . & . & . & . \\
\hline
\end{tabular}

\begin{tabular}{|c|c|c|c|c|c|c|c|c|c|c|c|c|c|c|c|c|c|c|c|c|c|c|c|c|c|c|c|}
\hline$-c l p C$ & 1557 & 1588 & 1605 & 1608 & 1621 & 1638 & 1641 & 1645 & 1669 & 1713 & 1719 & 1749 & 1752 & 1803 & 1807 & 1827 & 1836 & 1844 & 1854 & 1867 & 1878 & 1935 & 1972 & 1988 & 1990 & 2068 & 2078 \\
\hline \multicolumn{28}{|l|}{ Po wallikeri } \\
\hline Po 2006 & $\bar{T}$ & $\bar{T}$ & $\bar{T}$ & $\bar{T}$ & $\bar{A}$ & $\bar{T}$ & $\bar{A}$ & $\bar{C}$ & $\bar{C}$ & $\bar{T}$ & $\bar{A}$ & $\bar{A}$ & $\bar{T}$ & $\bar{T}$ & $\mathrm{C}$ & $\bar{T}$ & $\bar{T}$ & $\bar{T}$ & $\bar{G}$ & $\bar{T}$ & $\bar{A}$ & $\mathrm{~T}$ & $\bar{T}$ & $\bar{A}$ & $\bar{G}$ & $\mathrm{C}$ & $\bar{A}$ \\
\hline $\begin{array}{l}\text { Po 2012-3 } \\
\text { Po 2014-2 }\end{array}$ & . & . & . & . & . & . & . & . & . & . & . & . & . & . & . & . & . & . & . & . & . & . & . & . & . & . & \\
\hline \multicolumn{28}{|l|}{ Po curtisi } \\
\hline $\mathrm{AB} 649417$ & $T$ & A & $T$ & $T$ & A & $\bar{A}$ & $\bar{T}$ & $T$ & $\mathrm{C}$ & A & $T$ & $\bar{A}$ & $T$ & $T$ & $T$ & $\mathrm{C}$ & $T$ & $\mathrm{C}$ & $\bar{A}$ & $T$ & G & A & $\mathrm{C}$ & A & $\bar{A}$ & $\mathrm{C}$ & $\mathrm{G}$ \\
\hline AY634623 & . & . & . & . & . & . & . & . & . & . & . & & & & . & . & & . & . & & . & . & . & & . & & 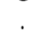 \\
\hline Po 2003 & . & & 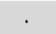 & & . & . & . & . & . & r & & & & & & & & & . & . & & & & & & & \\
\hline Po & . & . & . & & . & . & . & . & . & . & . & . & . & & & . & . & . & . & . & r & . & . & & & & \\
\hline Po & . & . & . & & . & . & . & . & . & . & . & . & . & & & . & . & . & . & . & . & . & . & & & & \\
\hline Po & . & & 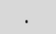 & & . & . & . & . & T & 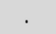 & r. & . & . & & & & 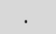 & 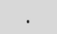 & . & . & . & . & T & & & & \\
\hline Po 2 & . & . & . & & . & . & . & . & . & . & . & . & . & & . & . & . & . & . & . & . & . & . & & & & \\
\hline & . & & . & & . & . & r & . & . & . & . & 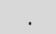 & . & & & & r & . & . & . & r & . & & & & & \\
\hline Po & . & . & . & & . & . & . & . & . & . & . & . & . & & . & . & . & . & . & . & . & . & T & . & & & \\
\hline Po 2014-1 & & & & & & & & & & & & & & & & & & & & & & & & & & & \\
\hline \multicolumn{28}{|l|}{ P. ovale like } \\
\hline HQ842632 & $\mathrm{C}$ & c & C & $A$ & G & $G$ & . & . & . & $T$ & . & G & $\bar{A}$ & $\bar{c}$ & & . & $\bar{c}$ & . & . & $\mathrm{c}$ & . & $\bar{T}$ & $T$ & G & & $\bar{T}$ & $\bar{A}$ \\
\hline
\end{tabular}

Fig. 7 Dimorphic nature of Plasmodium ovale curtisi and Plasmodium ovale wallikeri based on the partial sequences from two apicoplast genes. $\mathbf{a}$ tufA gene, and $\mathbf{b} C I P C$ gene. Each alignment includes the sequences from the P. ovale cases imported in Singapore (highlighted in grey) and published sequences. The Plasmodium ovale-like sequence [HQ842632] isolated from chimpanzee (Kaiser et al. unpublished) is included into this comparison but separated from P. o. curtisi and P. o wallikeri because it present 11 additional unique polymorphic loci beside the 15 dimorphic loci that distinguish P. o. curtisi and P. o wallikeri. Numbering is based on the start-codon (ATG) identified for both tufA and clpC. Non-synonymous mutations are in boldface type and dots represent nucleic acid similarity

19 dimorphic loci were found between $P$. o. curtisi and $P$. o. wallikeri.

\section{$c \mid p C$}

Three $c l p C$ sequences are available for $P$. ovale in GenBank: the full sequence extracted from [AB649417] [55], a partial sequence [AY634623] [56], and a sequence [HQ842632] (Kaiser et al. unpublished) from a P. ovalelike parasite detected in chimpanzee. These were compared to the sequences (GenBank accession numbers KP050438 to KP050448) of the 625-bp fragments amplified from the P. ovale imported cases (Fig. 7b). A total of 15 dimorphic loci were found between P. o. curtisi and P. o. wallikeri. Sequences [AB649417] and [AY634623] matched the $P$. o. curtisi parasites. However, for sequence [HQ842632], the variations were more diverse: of the 15 dimorphic loci, nine were similar to those of P. o. curtisi, four to those of $P$. $o$. wallikeri, and the remaining two loci differed from those previously noted for P. o. curtisi and $P$. o. wallikeri. Eleven additional mutations, three of which were non-synonymous, not previously observed in either P. o. curtisi and P. o. wallikeri, were also noted.

\section{Discussion}

The microscopic morphology of the parasite in stained blood smears is still considered to be the gold standard for the identification of Plasmodium species, and it is often the only technique available in clinical laboratories. However, the subtle morphological characteristics that help distinguish $P$. vivax and $P$. ovale are readily missed by less experienced microscopists, and might even elude expert microscopists who only encounter one or other of these two species infrequently or when the quality of the smears or the staining are sub-optimal [15, 38, 57]. Thus, it was not surprising that all the confirmed $P$. ovale cases in Singapore had been misidentified at $P$. vivax by the hospital laboratory staff that encounter Plasmodium parasites relatively infrequently. Current rapid diagnostic 
tests (RDTs) are inadequate for the direct identification of $P$. ovale [58] although some might be helpful in preventing confusion with $P$. vivax [59]. Accurate diagnosis of $P$. ovale remains dependent on the use of molecular techniques such as PCR. However, even the reliable and well-adopted protocols [39] used in the present study has been shown to miss certain $P$. ovale cases [60]. To prevent the risk of overlooking $P$. ovale, especially in mixed infection with others malaria species one might consider to choose a more sensitive protocol $[60,61]$. It should be noted that the misidentification of $P$. ovale as $P$. vivax, or vice versa, has little clinical consequence because the recommended treatment for both species is the same [62].

The imported $P$. ovale cases uncovered in this study were genetically characterized for markers (ssrRNA, Potra, Porbp2, Pog3p, dhfr-ts, cytb, cox1) used in other recent studies [23-26]. The data were concordant with those previously obtained and allowed them to be clearly identified as $P$. o. curtisi or as $P$. o. wallikeri. For the ssrRNA, dhfr-ts and Potra genes, synonymous and nonsynonymous polymorphisms were noted within the sequences obtained for the $P$. o. curtisi or the $P$. $o$. wallikeri samples. These variations were broadly more numerous for the $P$. o. wallikeri sequences; however, a higher number of samples will be required to confirm this trend. These observations indicate that 'sub-types' of $P$. $o$. curtisi and $P$. o. wallikeri might occur $[23,24,26,50,63,64]$ in humans and in chimpanzees. Analysis of a larger number of samples from humans and chimpanzees will be needed to test the hypothesis that a 'P. ovale species complex' is shared between humans and apes.

In the present study the genetic characterization was extended to three other genes that proved to be dimorphic between the two $P$. ovale species. The nuclear asl gene (encoding adenylosuccinate lyase) had the highest number of dimorphic loci in comparison with the other genes analysed, and displayed no internal variations within either the Poc or the Pow samples. These observations are consistent with the notion that $P$. o. curtisi and P. $o$. wallikeri have been evolving separately over a long period of time [23]. The other two genes analysed (tufA and $\operatorname{clp} C$ ) are present on the apicoplast, whose genome has only been previously characterized for the Nigeria II $P$. ovale isolate [56]. A phylogenetic analysis of the asl fragments built from the 15 sequences obtained in this study from cases imported into Singapore and from other sequences from various P. ovale and other Plasmodium species (downloaded from GenBank) that infect humans, apes, non-human primates, rodents, and birds showed that both $P$. ovale species cluster into a biphyletic clade that is related to other Plasmodium species of primates. This observation, based on a single nuclear gene, was congruent with the conclusions derived from analyses of the mitochondrial genome [26, 65, 66], but they did not support the recent suggestion, based on the analyses of the apicoplast genome, that $P$. ovale is closely related to the Plasmodium species of African rodents [56]. It also emphasizes that it would be desirable to adopt an approach based on multiple genes across several genomes, using a larger number of samples for each species, in order to increase the likelihood of deriving a true phylogenetic relationship between the various Plasmodium species [45].

All the confirmed P. ovale cases discovered in Singapore were imported from endemic areas for this species [12] from eight countries (six in Africa and two in South and Southeast Asia) where this parasite has been previously recorded: Nigeria [67], Central African Republic [68], Uganda [10, 69], Ivory Coast [70], Cameroon [71], Equatorial Guinea [72], Liberia [6], India [72, 73], and Indonesia $[74,75]$. The one case imported from India is interesting in that although $P$. ovale was first reported in this country 75 years ago, albeit as a doubtful mixed infection with $P$. falciparum [72], it has been reported since only five times [73, 76-79]. It is not at present clear whether this suggests that this parasite species is on the increase in India or whether its prevalence has been grossly underestimated through misidentification as $P$. vivax. The case imported from Indonesia is equally interesting in that the patient had probably acquired the infection in Sumatra where $P$. ovale had not previously been recorded $[5,75]$.

Plasmodium vivax is consistently the species most frequently imported in Singapore (70 \%, 1512 of the 2155 cases recorded between 2001 and 2014). Until the present study $P$. ovale infections had not been officially reported in Singapore, although a suspected diagnosis was made on two occasions in 1998 and in 2013 but not confirmed by MRC. For the period 2009-2011, molecular analysis of the 511 malaria-positive samples (386 identified as $P$. vivax by morphology) did not reveal any $P$. ovale infections, whereas nine $P$. ovale infections (four in 2012, three in 2013 and two in 2014) were detected from all the cases recorded in the last three years (316 cases with 238 identified as $P$. vivax by morphology in 2012-2014). For the period 2001-2008, a total of 1328 malaria-positive cases (888 identified as $P$. vivax by morphology) were notified to $\mathrm{MOH}$, but only 226 frozen blood samples were available from this period (150 were identified as P. vivax by morphology) for molecular testing, revealing that two were actually $P$. ovale (one in 2003 and another in 2006). If one assumes the same proportion of misidentified $P$. ovale for the remaining 1,102 samples, then the expected total number of potential $P$. ovale cases for the 2001-2011 period would be 12 out of the 1,835 recorded cases. Thus, it is possible that there has been a sharp 
increase in the proportion of $P$. ovale recently imported to Singapore (an estimated $0.65 \%$ for $2001-2011$ versus $2.85 \%$ for 2012-2014). Such an increase would be puzzling given the constant decrease in the total number of malaria cases recorded in Singapore since 2010 [80]. This pattern does not seem to be restricted to Singapore, with similar, recent reports of $P$. ovale in imported malaria cases among soldiers deployed in endemic areas [16, 81], tourists visiting endemic countries [82, 83], and foreign workers returning from endemic regions [84-86]. Several hypotheses, alone or in combination, might be for formulated to explain such an increase: (1) an upsurge of studies employing molecular tools that allow sensitive and accurate detection and identification of Plasmodium species (this would not apply to the cases imported to Singapore over the last 6 years, because all were molecularly tested); (2) an increase over recent years in the number of travellers, visitors or migrant workers to $P$. ovale-endemic countries; and, (3) a recent increase in the prevalence of $P$. ovale in the endemic areas, possibly as a result of extensive campaigns directed against $P$. falciparum that might favour this less common species as suggested by [15] or as observed with the recent increase of $P$. knowlesi in Malaysia [87].

\section{Public health concern in Singapore}

Plasmodium ovale can induce relapses that can occur a long time after the primary infection and over several years $[5,9,88]$. Six of the nine imported cases to Singapore in recent years were clearly due to relapsing $P$. ovale that had been acquired a few months to 4 years previously. Given the presence of competent mosquito vectors such as Anopheles maculatus in Singapore [89] and the possibility of relapse episodes long after the primary infection $[5,9,88]$ some of which are potentially asymptomatic, clinicians, epidemiologists, laboratory technicians, and public health officials should place $P$. ovale on a par with $P$. vivax as a potential threat to malaria elimination programmes [31, 82, 90, 91].

\section{Conclusion}

Routine malaria surveillance, incorporating molecular species determination performed by the MRC-NPHL, detected nine $P$. ovale infections that had been misidentified in clinical laboratories settings as $P$. vivax among malaria cases imported to Singapore over the last 3 years. This is the first confirmed report of $P$. ovale in Singapore. Retrospective study on archived blood samples identified two additional misidentified $P$. ovale infections: one in 2003 and another in 2006. Both P. o. curtisi and P. o. wallikeri were found among the cases imported to Singapore, and their genetic dimorphism was confirmed using ten markers spread across the parasites' three genomes (seven previously analysed in other studies and three additional ones that were not characterized before). The data suggest that there might have been an apparent increase in the proportion of imported $P$. ovale in the face of a decrease in the overall number of malaria cases recorded in Singapore. Given its ability to cause relapses, $P$. ovale should not be neglected as a public health concern.

\section{Additional file}

Additional file 1. Details about misidentifications, travel histories, onsets and symptoms of the Plasmodium ovale cases recorded in Singapore.

\section{Authors' contributions}

JMC designed the study; JMC and SBHT processed the samples and run the tests; JMC and GS analysed the data; JMC and GS drafted the manuscript; RTPVL approved the study. All the authors have read and approved the final manuscript.

\section{Author details}

${ }^{1}$ Malaria Reference Centre - National Public Health Laboratory, Ministry of Health, Singapore, 3 Biopolis Drive, Synapse \#05-14/16, 138623 Singapore, Singapore. ${ }^{2}$ Sorbonne Universités, UPMC Université Paris 06, UPMC UMRS CR7, 75005 Paris, France. ${ }^{3}$ Centre d'Immunologie et de Maladies Infectieuses (CIMI) Paris, Institut National de la Santé et de la Recherche Médicale (Inserm) U1135, Centre National de la Recherche Scientifique (CNRS) ERL 8255, 75013 Paris, France. ${ }^{4}$ Department of Laboratory Medicine, National University Hospital, 5 Lower Kent Ridge Road, 119074 Singapore, Singapore. ${ }^{5}$ Department of Microbiology, Yong Loo Lin School of Medicine, National University of Singapore, 5 Science Drive 2, Block MD4, Level 3, 117545 Singapore, Singapore.

\section{Acknowledgements}

The authors are grateful to all the Public Health Officers from the Surveillance and Response Branch of the Communicable Diseases Division of the Ministry of Health for their help in providing epidemiological data and case histories of patients from whom the samples were obtained.

\section{Competing interests}

The authors declare that they have no competing interests.

Received: 8 September 2015 Accepted: 3 November 2015

Published online: 14 November 2015

References

1. Stephens JWW. A new malaria parasite of man. Ann Trop Med Parasitol. 1922;16:383-8.

2. Giovannola A. Plasmodium ovale considered as a modification of Plasmodium vivax after a long residence in the human host. Am J Trop Med Hyg. 1935;15:175-86.

3. James SP, Nicol WD, Shute PG. The specific status of Plasmodium ovale Stephens. Am J Trop Med Hyg. 1935;15:187-8.

4. Lau YL, Lee WC, Tan LH, Kamarulzaman A, Syed Omar SF, Fong MY, et al. Acute respiratory distress syndrome and acute renal failure from Plasmodium ovale infection with fatal outcome. Malar J. 2013;12:389.

5. Collins WE, Jeffery GM. Plasmodium ovale: parasite and diseases. Clin Microbiol Rev. 2005;18:570-81.

6. Yorke W, Owen DV. Plasmodium ovale. Am J Trop Med Hyg. 1930;24:93.

7. Chin W, Coatney GR. Relapse activity of mosquito-induced infections with a West African strain of Plasmodium ovale. Am J Trop Med Hyg. 1971;20:825-7.

8. Collins WE, Jeffery GM. A retrospective examination of sporozoite- and trophozoite-induced infections with Plasmodium ovale: development of 
parasitologic and clinical immunity during primary infection. Am J Trop Med Hyg. 2002;66:492-502.

9. Garnham PCC. Malaria parasites and others Haemosporidia. Oxford: Blackwell Scientific Publication 1966. p 1164.

10. Onori E. Distribution of Plasmodium ovale in eastern, western and northern regions of Uganda. Bull World Health Organ. 1967;37:665-8.

11. Baufine-Ducrocq H, Couzineau P, Rousset JJ. [Plasmodium ovale Stephens, 1922](in French). Ann Parasitol Hum Comp. 1969;44:273-328.

12. Lysenko AJA, Beljaev AE. An analysis of the geographical distribution of Plasmodium ovale. Bull World Health Organ. 1969;40:383-94.

13. Cornu M, Combe A, Couprie B, Moyou-Somo R, Carteron B, Van Harten $\mathrm{WH}$, et al. [Epidemiological aspect of malaria in 2 villages of Manyemen forest region (Cameroon, southwest province)](in French). Med Trop (Mars). 1986;46:131-40.

14. Faye FB, Konate L, Rogier C, Trape JF. Plasmodium ovale in a highly malaria endemic area of Senegal. Trans R Soc Trop Med Hyg. 1998;92:522-5.

15. Mueller I, Zimmerman PA, Reeder JC. Plasmodium malariae and Plasmodium ovale - the 'bashful' malaria parasites. Trends Parasitol. 2007;23:278-83.

16. De Laval F, Oliver M, Rapp C, Pommier de Santi V, Mendibil A, Deparis X, et al. The challenge of diagnosis Plasmodium ovale malaria in travellers: report of six clustered cases in French soldiers returning from West Africa. Malar J. 2010;9:358.

17. Snounou G, Pinheiro L, Gonçalves A, Fonseca L, Dias F, Brown KN, et al. The importance of sensitive detection of Malaria parasites in the human and insect hosts in epidemiological studies, as shown by the analysis of field samples from Guinea Bissau. Trans R Soc Trop Med Hyg. 1993:87:649-53.

18. Zhou M, Liu Q, Wongsrichanalai C, Suwonkerd W, Panart K, Prajakwong $\mathrm{S}$, et al. High prevalence of Plasmodium malariae and Plasmodium ovale in malaria patients along the Thai-Myanmar border, as revealed by acridine orange staining and PCR-based diagnoses. Trop Med Intl Health. 1998:3:304-12.

19. Mueller I, Widmer S, Michel D, Maraga S, McNamara DT, Kiniboro B, et al. High sensitivity detection of Plasmodium species reveals positive correlations between infections of different species, shifts in age distribution and reduced local variation in Papua New Guinea. Malar J. 2009;8:41.

20. Betson M, Sousa-Figueiredo J, Atuhaire A, Arinaitwe M, Adriko M, Mwesigwa G, et al. Detection of persistent Plasmodium spp. infections in Ugandan children after artemether-lumefantrine treatment. Parasitology. 2014;141:1880-90.

21. Tachibana M, Tsuboi T, Kaneko O, Khuntirat B, Torii M. Two types of Plasmodium ovale defined by SSUrRNA have distinct sequences for ookinete surface proteins. Mol Biochem Parasitol. 2002;122:223-6.

22. Win TT, Jalloh A, Tantular IS, Tsuboi T, Ferreira MU, Kimura M, et al. Molecular analysis of Plasmodium ovale variants. Emerg Infect Dis. 2004;10:1235-40.

23. Sutherland CJ, Tanomsing N, Nolder D, Oguike M, Jennison C, Pukrittayakamee $\mathrm{S}$, et al. Two nonrecombining sympatric forms of the human malaria parasite Plasmodium ovale occur globally. J Infect Dis. 2010;201:1544-50.

24. Oguike MC, Betson M, Burke M, Nolder D, Stothard JR, Kleinschmidt I, et al. Plasmodium ovale curtisi and Plasmodium ovale wallikeri circulate simultaneously in African communities. Int J Parasitol. 2011;41:677-83.

25. Fuehrer HP, Habler VE, Fally MA, Harl J, Starzengruber P, Swoboda P, et al. Plasmodium ovale in Bangladesh: genetic diversity and the first known evidence of the sympatric distribution of Plasmodium ovale curtisi and Plasmodium ovale wallikeri in southern Asia. Int J Parasitol. 2012;42:693-9.

26. Duval L, Nerrienet E, Rousset, Sadeuh Mba SA, Houzé S, Fourment M, et al. Chimpanzee malaria parasites related to Plasmodium ovale in Africa. PLoS One. 2009;4:e5520.

27. Goh KT. Epidemiological surveillance of communicable diseases in Singapore/by KT Goh. SEAMIC publication, no. 35, Ed. C. Southeast Asian Medical Information. 1983. Tokyo.

28. Vickers WJ. Annual report of Medical Department, Colony of Singapore. 1946; p 14.

29. Nah WT, Chew PK. A historical review of environmental health work in Singapore. Singapore Public Health Bull. 1972;10:30-4.

30. Teo BT, Miles C, Alias O. A review of anti-malarial drainage in Singapore city since 1911. Singapore Public Health Bull. 1972;9:33-9.
31. Lee YC, Tang CS, Ang LW, Han HK, James L, Goh KT. Epidemiological characteristics of imported and locally-acquired malaria in Singapore. Ann Acad Med Singapore. 2009;38:840-9.

32. Ng LC, Lee KS, Tan CH, Ooi PL, Lam-Phua SG, Lin RTPV, et al. Entomologic and molecular investigation into Plasmodium vivax transmission in Singapore, 2009. Malar J. 2010;9:305.

33. Ng OT, Ooi EE, Lee CC, Lee PJ, Ng LC, Pei SW, et al. Naturally acquired human Plasmodium knowlesi infection, Singapore. Emerg Infect Dis. 2008;14:814-6.

34. Quek DL, Zhang Y, La MV, Fernandez PP, Chavatte J-M. Laboratory test results on Plasmodium knowlesi in clinical malaria positive cases registered in 2009 in Singapore. Epidemiol News Bull. 2010;36:83-94.

35. Wong PSJ, Tan CH, Lee V, Li MZI, Lee KS, Lee PJ, et al. Molecular epidemiological investigation of Plasmodium knowlesi in Humans and Macaques in Singapore. Vector Borne Zoonotic Dis. 2011;11:131-5.

36. Shute GT. The microscopic diagnosis of malaria. In: Wernsdorfer WH, McGregor I, editors. Malaria: principles and practice of malariology, Vol1. Edinburgh: Churchill Livingston; 1988. p. 781-814.

37. World Health Organization. Bench aids for Malaria Microscopy. 1st Edition. WHO Library. 2009; p 24.

38. World Health Organization. Basic malaria microscopy—Part 1. Learner's guide. 2nd Edn. WHO Library. 2010; p 80.

39. Snounou G, Singh B. Nested PCR analysis of Plasmodium parasites. Meth Mol Med. 2002;72:189-203.

40. Safeuki I, Millet P, Boucher S, Melinard L, Fregeville F, Receveur MC, et al. Evaluation of FRET real-time PCR assay for rapid detection and differentiation of Plasmodium species in returning travellers and migrants. Malar J. 2008;7:70.

41. Imwong M, Tanomsing N, Pukrittayakamee S, Day NP, White NJ, Snounou G. Spurious amplification of a Plasmodium vivax small-subunit RNA gene by use of primers currently used to detect Plasmodium knowlesi. J Clin Microbiol. 2009;47:4173-5.

42. Tanomsing N, Imwong M, Pukrittayakamee S, Chotivanich K, Looareesuwan S, Mayxay M, et al. Genetic analysis of the Dihydrofolate ReductaseThymidylate Synthase gene from geographically diverse isolates of Plasmodium malariae. Antimicrobial Agent Chemother. 2007;51:3523-30.

43. Perkins SL, Schall JJ. A molecular phylogeny of malarial parasites recovered from cytochrome b gene sequences. J Parasitol. 2002;88:972-8.

44. Perkins SL, Sarkar IN, Carter R. The phylogeny of rodent malaria parasites: simultaneous analysis across three genomes. Infect Gen Evol. 2007;7:74-83.

45. Coatney GR, Collins WE, Warren M, Contacos PG. CD-ROM-The Primate Malarias [Original book published 1971]. Division of Parasitic Diseases, producers. Version 1.0. Atlanta, GA: CDC; 2003.

46. Wilcox A, Jeffery GM, Young MD. The Donaldson strain of malaria. 2. Morphology of the erythrocytic parasites. Am J Trop Med Hyg. 1954;3:638-49.

47. Sinton JA. Morphology of the parasitized erythrocyte in infection with Plasmodium ovale. Trans R Soc Trop Med Hyg. 1955;49:286-7.

48. Qari SH, Shi YP, Pieniazek NJ, Collins WE, Lal AA. Phylogenetic relationship among the malaria parasites based on the small subunit rRNA gene sequences: monophyletic nature of the human malaria parasite, Plasmodium falciparum. Mol Phylogenet Evol. 1996;6:157-65.

49. Tanomsing N, Imwong N, Sutherland CJ, Dolecek C, Tran TH, Nosten F, et al. Genetic marker suitable for the identification and genotyping of Plasmodium ovale curtisi and Plasmodium ovale wallikeri. J Clin Microbiol. 2013;51:4213-6.

50. Tirakarn S, Riangrungroj P, Kongsaeree P, Imwong M, Yuthavong Y, Leartsakulpanich U. Cloning and heterologous expression of Plasmodium ovale dihydrofolate reductase-thymidylate synthase gene. Parasitol Int. 2012;61:324-32.

51. Marshall VM, Coppel RL. Characterisation of the gene encoding adenylosuccinate lyase of Plasmodium falciparum. Mol Biochem Parasitol. 1997;88:237-41.

52. Kedzierski L, Escalante AA, Isea R, Black CG, Barnwell JW, Coppel RL. Phylogenetic analysis of the genus Plasmodium based on the gene encoding adenylosuccinate lyase. Infect Gen Evol. 2002;1:297-301.

53. Tanabe K, Mita T, Jombart T, Eriksson A, Horibe S, Palacpac N, et al. Plasmodium falciparum accompanied the human expansion out of Africa. Curr Biol. 2010;20:1283-9. 
54. Liu W, Li Y, Shaw KS, Learn GH, Plenderleith LJ, Malenke JA, et al. African origin of the malaria parasite Plasmodium vivax. Nat Commun. 2014;5:3346.

55. Arisue N, Hashimoto T, Mitsui H, Palacpac NM, Kaneko A, Kawai S, et al. The Plasmodium apicoplast genome: conserved structures and close relationship of $P$. ovale to rodent malaria parasites. Mol Biol Evol. 2012;29:2095-9.

56. Hagner SC, Misof B, Maier L, Kampen H. Bayesian analysis of new and old malaria parasite DNA sequence data demonstrates the need for more phylogenetic signal to clarify the descent of Plasmodium falciparum. Parasitol Res. 2007;101:493-503.

57. Obare P, Ogutu B, Adams M, Odera JS, Lilley K, Dosoo D, et al. Misclassification of Plasmodium infections by conventional microscopy and the impact of the remedial training on the proficiency of laboratory technicians in species identification. Malar J. 2013;12:113.

58. Bigaillon C, Fontan E, Cavallo JD, Hernandez E, Spiegel A. Ineffectiveness of the Binax NOW malaria test for the diagnosis of Plasmodium ovale malaria. J Clin Microbiol. 2005;43:1011.

59. Gillet P, Bosselaers K, Cnops L, Bottieau E, Van Esbroeck M, Jacob J. Evaluation of the SD FK70 malaria Ag Plasmodium vivax rapid diagnostic test in non endemic setting. Malar J. 2009;8:129.

60. Calderaro A, Piccolo G, Perandin F, Gorrini C, Peruzzi S, Zuelli C, et al. Genetic polymorphisms influence Plasmodium ovale PCR detection accuracy. J Clin Microbiol. 2007:45:1624-7.

61. Fuehrer HP, Stadler MT, Buczolich K, Bloeschl I, Noedl H. Two techniques for simultaneous identification of Plasmodium ovale curtisi and Plasmodium ovale wallikeri by use of the small-subunit rRNA gene. J Clin Microbiol. 2012;50:4100-2.

62. World Health Organization. Guidelines for the treatment of MalariaAnnex 10. Treatment of P. vivax, P. ovale and P. malariae infections. WHO Library 2006; p 266.

63. Kaiser M, Löwa A, Ulrich M, Ellerbrok H, Goffe AS, Blasse A, et al. Wild chimpanzees infected with 5 Plasmodium species. Emerg Infect Dis. 2010;16:1956-9.

64. Li M, Xia Z, Yan H. New types of SSUrDNA sequence was detected from both Plasmodium ovale curtisi and Plasmodium ovale wallikeri samples. Malar J. 2014:13:216.

65. Krief S, Escalante AA, Pacheco MA, Mugisha L, André C, Halbax M, et al. On the diversity of malaria parasites in African Apes and the origin of Plasmodium falciparum from Bonobos. PLoS Path. 2010;6:e1000765.

66. Pacheco MA, Battistuzzi FU, Junge RE, Cornejo OE, Williams CV, Landau I, et al. Timing the origin of human malarias: the lemur puzzle. BMC Evol Biol. 2011;11:299.

67. Stephens JWW, Owen DV. Plasmodium ovale. Am J Trop Med Parasitol. 1927;21:293-302.

68. Lacan A, Peel E. Plasmodium ovale Stephen, 1922 en Afrique équatoriale française. Bull Soc Path Exot. 1958;51:167-9.

69. Manson-Bahr P, Huggleton WH. Plasmodium ovale infection contracted in different parts of west and central Africa. BMJ. 1937;1:217-8.

70. Escudie A, Hamon J. Le paludisme en Afrique occidentale d'expression française. Med Trop (Mars). 1961;21:661-87.

71. Bock E. Zur epidemiologie, klinik und parasitologie der durch das Plasmodium ovale Stephen, 1922 hervorgerufenen malaria. Arch Schiffs Tropen Hyg. 1939;43:327-52.

72. Raman TK. Plasmodium ovale in India. J Indian Med Ass. 1940;9:583-5.

73. Mukherjea AK, Chatterjee PK, Paul SC. A case of Plasmodium ovale infection. Bull Calcutta Sch Trop Med. 1966;14:88-9.
74. Gundelfinger BF, Wheeling $\mathrm{CH}$, Lien JC, Atmosoedjono S, Simanjuntak $\mathrm{CH}$. Observation on malaria in Indonesian Timor. Am J Trop Med Hyg. 1975;24:393-6.

75. Baird JK, Purnomo, Masbar S. Plasmodium ovale in Indonesia. Southeast Asian J Trop Med Publ Health. 1990;21:541-4.

76. Jabulingam P, Mohapatra SS, Das LK, Das Pk, Rajagopalan PK. Detection of Plasmodium ovale in Koraput district, Orissa state. Indian J Med Res. 1989:89:115-6.

77. Mishra B, Mirdha BR, Samantray JC. Plasmodium ovale malaria in Delhi. Indian J Pediatr. 1999;66:143-4.

78. Prakash A, Mohapatra PK, Bhattacharyya DR, Goswami BK, Mahanta J. Plasmodium ovale: first case report from Assam, India. Curr Sci. 2003;84:1187-8.

79. Marathe A, Date V, Shah HN, Tripathi JR. Plasmodium ovale — a case report from Gujarat. J Vector Borne Dis. 2006;43:206-8.

80. Ministry of Health, Singapore. Communicable Diseases Surveillance in Singapore 2013. MOH Communicable Diseases Division 2014; p 142.

81. Mellon G, Ficko C, Thellier M, Kendjo E, Aoun O, Adriamanantena D, et al Two cases of late Plasmodium ovale presentation in military personnel. J Travel Med. 2014;21:52-4.

82. Lim YAL, Mahmud R, Chew CH, Thiruventhiran T, Chua KH. Plasmodium ovale infection in Malaysia: first imported case. Malar J. 2010;9:272.

83. Baranova AM. [The vivax malaria causative agent Plasmodium ovale: the present global area, intraspecies polymorphism, importation to the Russian Federation (1992-2011)] (in Russian). Med Parazitol (Mosk) 2012:3:45-9.

84. Li Y, Wang G, Sun D, Meng F, Lin S, Hu X, et al. A case of Plasmodium ovale wallikeri infection in a Chinese worker returning from West Africa. Korean J Parasitol. 2013:51:557-62.

85. Zhang XH, Ni QX, Chen Y, Yao LN, Lu QY, Yu XH, et al. [Diagnosis and analysis of the first imported ovale malaria case in Wenzhou City] (in Chinese). Zhongguo Ji Sheng Chong Xue Yu Ji Sheng Chong Bing Za Zhi. 2013;31:380-1.

86. Shi YX, Huang JC, Su JK, Li XB, Zheng K, Ding GY. [Diagnosis of the first imported case of Plasmodium ovale infection at Guangdong Port] (in Chinese). Zhongguo Ji Sheng Chong Xue Yu Ji Sheng Chong Bing Za Zhi. 2014;32:156-8.

87. William T, Rahman HA, Jelip J, Ibrahim MY, Menon J, Grigg MJ, et al. Increasing incidence of Plasmodium knowlesi Malaria following Control of P. falciparum and P. vivax Malaria in Sabah, Malaysia. PLoS Negl Trop Dis. 2013;7:e2026

88. Limongi JE, Costa DC, Carvalho LH, Lopes IS, Silva AA, Ferreira MS. Plasmodium ovale malaria in Brazil: report of an imported case with a prolonged incubation period. J Infect Dev Ctries. 2014:15:554-7.

89. Goh KT. Eradication of malaria from Singapore. Singapore Med J. 1983:24:265-8.

90. Ooi PL, Goh KT, Lee KM. Local transmission of Plasmodium vivax malaria in Singapore. Ann Acad Med Singapore. 1997;26:588-92.

91. Hombhanje FW. Plasmodium ovale species in Papua New Guinea-lest we forget. PNG Med J. 1998;41:116-8.

\section{Submit your next manuscript to BioMed Central and take full advantage of:}

- Convenient online submission

- Thorough peer review

- No space constraints or color figure charges

- Immediate publication on acceptance

- Inclusion in PubMed, CAS, Scopus and Google Scholar

- Research which is freely available for redistribution

Submit your manuscript at

www.biomedcentral.com/submit
C Biomed Central 